\title{
Poor Validity of Functional Performance Tests to Predict Knee Injury in Female Soccer Players With or Without Anterior Cruciate Ligament Reconstruction
}

Anne Fältström, Martin Hägglund, Henrik Hedevik and Joanna Kvist

The self-archived postprint version of this journal article is available at Linköping University Institutional Repository (DiVA):

http://urn.kb.se/resolve?urn=urn:nbn:se:liu:diva-175990

N.B.: When citing this work, cite the original publication.

Fältström, A., Hägglund, M., Hedevik, H., Kvist, J., (2021), Poor Validity of Functional Performance Tests to Predict Knee Injury in Female Soccer Players With or Without Anterior Cruciate Ligament Reconstruction, American Journal of Sports Medicine, 49(6), 1441-1450.

https://doi.org/10.1177/03635465211002541

Original publication available at:

https://doi.org/10.1177/03635465211002541

Copyright: SAGE Publications

http://www.uk.sagepub.com/home.nav 


\section{Poor Validity of Functional Performance Tests to Predict Knee}

\section{Injury in Female Soccer Players With or Without Anterior}

\section{Cruciate Ligament Reconstruction}

Background: Various tests have been developed to evaluate athletes' functional performance and for use as screening tools for injury prediction. Further validation of their accuracy to predict injury is needed.

Purpose: To investigate the validity of predetermined cutoffs used to differentiate between high and low-risk players in different functional performance tests to predict (1) anterior cruciate ligament (ACL) injury or (2) severe traumatic knee injury in a cohort of female soccer players with a primary unilateral ACL reconstruction and a cohort of knee-healthy players.

Study Design: Cohort study.

Methods: 117 active female soccer players (mean age \pm standard deviation, $20 \pm 2$ years) $19 \pm 9$ months after ACL reconstruction and 119 knee-healthy players (age $19 \pm 3$ years) were prospectively followed up for 2 years for new knee injuries. At baseline, all players underwent tests to assess postural control (Star Excursion Balance Test), hop performance (1legged hop for distance, side hop), and movement asymmetries in the lower limbs and trunk (drop vertical jump [DVJ], tuck jump). The predictive validity of the test cutoffs to identify players who would sustain an ACL injury, or a severe traumatic knee injury (absence from soccer play $>28$ days), was assessed. Risk ratios (RR), area under the receiver operating characteristic curve (AUC), sensitivity, and specificity were calculated. 
Results: Forty-six players with ACL reconstruction (39\%) sustained 48 severe knee injuries, including $28 \mathrm{ACL}$ ruptures. Of the knee-healthy players, 13 (11\%) sustained 14 severe knee injuries, including 8 ACL ruptures. No association was found between the predetermined functional performance test cutoffs and risk of a new ACL injury or severe knee injury in players with ACL reconstruction. In knee-healthy players, the only variable associated with future ACL injury was $\geq 6.5 \mathrm{~cm}$ knee valgus in the frontal plane (any knee) at DVJ (RR, 4.93; $95 \% \mathrm{CI}, 1.04-23.40 ; P=.045$ ) but with only fair predictive validity; $\mathrm{AUC}=0.7$, sensitivity $=0.75$, specificity $=0.65$.

Conclusions: In our cohorts of female soccer player, the validity of commonly used functional performance tests to predict new knee injuries were poor. Only knee valgus during the DVJ was associated with new ACL injury in knee-healthy players but only with fair predictive validity.

Keywords: female; football; soccer; anterior cruciate ligament; return to sports; reinjury; predictor

\section{What is known about the subject}

Different cutoffs, to indicate a satisfactory result and to differentiate between high and lowrisk players, in commonly used functional performance tests have been created from different cohorts in prospective studies. These cutoffs are often used when evaluating functional performance and to predict injuries both in injured, e.g., in players with anterior cruciate ligament (ACL) injury or reconstruction, and uninjured players. However, the validity of the cutoffs to predict injury is unclear, and the existing literature has several limitations with low numbers of participants and events included, and differences in ages, sports, test criteria, and competition levels. The cutoffs in functional performance tests need further validation in new 
and relevant populations regarding their ability to predict a primary and secondary knee injury.

\section{What this study adds to existing knowledge}

The validity of predetermined cutoffs used to differentiate between high and low-risk players in commonly used functional performance tests that assess postural control, hop performance, and movement asymmetries was poor and could not predict future ACL injury or other severe knee injury. We evaluated the predictive validity of 5 different functional performance tests with a total of 10 cutoffs in 2 cohorts: female soccer players with or without ACL reconstruction. Only 1 cutoff from 1 functional performance test showed some predictive validity in 1 of the cohorts. Knee valgus $\geq 6.5 \mathrm{~cm}$ in any knee in the frontal plane measured during the drop vertical jump, in the cohort of knee-healthy players, was associated with 5 times higher risk for sustaining an ACL injury. However, the sensitivity and specificity of this test was only fair. Thus, the value of commonly used cutoffs in functional performance tests to predict injuries is poor.

\section{INTRODUCTION}

Different tests and test batteries have been developed to evaluate function, movement asymmetries, and to identify athletes at risk of sustaining injury to the lower extremity, especially to the knee. ${ }^{4,28,35,36}$ The most commonly used tests to evaluate knee function are quadriceps strength tests ${ }^{14,15,22,25,39,46}$ and hop tests (e.g., single hop for distance, timed hop, triple hop for distance, and cross-over hop for distance). ${ }^{14,15,22,25,39,46}$ Evaluation of trunk, hip, and knee valgus motion during sport-specific activities has been in focus regarding the possibility of identifying female athletes at high risk of primary ${ }^{20,23,26,35}$ or secondary $^{23,37}$ anterior cruciate ligament (ACL) injury. 
Cutoffs have been proposed for the different tests to help clinicians benchmark results for their athletes, for instance as part of pre-season screening or in return to sports (RTS) after an injury. Strength and hop performance are often measured and reported with a Limb Symmetry Index (LSI) and with a cutoff of $\geq 90 \%$ for a satisfactory result. ${ }^{6,10,16,41}$ However, the validity of these cutoffs to predict injury is unclear. Two recent systematic reviews on functional performance testing after ACL reconstruction (ACLR) highlighted the poor prognostic value of reaching specific cutoffs in the tests for clearance to RTS and risk of a new ACL injury ${ }^{27,44}$ and other additional knee injury. ${ }^{44}$ Overall, RTS clearance based on results of test batteries was not associated with reduced subsequent risk of ACL or knee injury. These systematic reviews included only 4 and 5 studies, respectively (a total of 6 studies) ${ }^{14,15,25,34,39,46}$ with a small number of participants. The authors ${ }^{27,44}$ highlighted the need to further study the prognostic value of the test batteries to predict ACL injury ${ }^{27,44}$ and new knee injury. ${ }^{44}$

Two factors are important to validate a screening test to predict sports injuries: (1) a strong relationship between the result from a screening test and risk to sustain an injury; validation of established cutoffs for different tests in relevant populations using appropriate statistical tools. ${ }^{3}$ The aim of this study (secondary analyses of a prospective cohort study) was to investigate the validity of 10 predetermined cutoffs in 5 different functional performance tests to predict (1) an ACL injury or (2) a severe traumatic knee injury in 2 different cohorts of active female soccer players, one cohort with primary unilateral ACLRs and one cohort with knee-healthy players. 


\section{MATERIALS AND METHODS}

\section{Participants}

A total of 117 active female soccer players (mean age \pm standard deviation, $20 \pm 2$ years) on average $19 \pm 9$ months after ACLR and 119 knee-healthy players (age, $19 \pm 3$ years) were included. The players with ACLR were identified from the Swedish National Knee Ligament Register (SNKLR). The registry captures over $90 \%$ of all ACLRs performed in Sweden. ${ }^{24} \mathrm{We}$ also advertised the study on 3 regional soccer district websites to include players with ACLR who were not registered in the SNKLR. The knee-healthy players were recruited by coaches from the same teams as the players with ACLR (matched to playing position and age). Teams participated at various playing levels from elite to amateur series. All players were included in the study at the same time point of the soccer pre-season (January to April) and were followed over 2 years or to the date they quit soccer if this occurred within the 2-year follow-up. Exclusion criteria in the ACLR group were additional previous ipsilateral or contralateral ACLRs, associated posterior cruciate ligament injury, and/or surgically treated injuries to either the medial or lateral collateral ligament of the knee.

All players received written and oral information about the study and signed informed consent form. The study was approved by the Swedish Ethical Review Authority (Dnr 2012/24-31 and 2013/75-32) and the SNKLR board. For a detailed description of the inclusion procedure and descriptive data for the cohort, see previously published data. ${ }^{10,11}$

\section{Follow-up}

During the 2-year follow-up, players were asked to register new traumatic (acute onset) or non-traumatic (insidious onset without any known trauma) knee injuries and absence from soccer play. Our injury definition was "any physical complaint sustained by a player 
irrespective of the need for medical attention or time-loss from soccer activities." 9 Absence from soccer play $>28$ days was classified as a severe knee injury. Players also registered whether they received medical attention (e.g., emergency medical care, primary care, specialist care [e.g., orthopedics, physiotherapy]) for the knee injury or physical complaint. If the player sustained a new knee injury, she was contacted by telephone for further information, and confirmation of the diagnosis was retrieved from medical charts. Confirmation from medical charts was complete for all knee injuries.

\section{Functional Performance Tests}

At baseline, all players performed functional performance tests to assess postural control (Star Excursion Balance Test [SEBT], ${ }^{38}$ ), hop performance (1-legged hop for distance ${ }^{16}$ and side hop ${ }^{16}$ ) and movement asymmetries in the lower limbs and trunk (tuck jump ${ }^{29}$ and drop vertical jump $[\mathrm{DVJ}]^{30-32}$ ). All players were tested by the same experienced tester (A.F.) according to a standardized test protocol. Indoor shoes were used in all tests except the SEBT, where players were barefoot. A detailed description of the tests is presented in Figure $1 .^{10}$

\section{Predetermined Cutoffs}

Predetermined cutoffs for the different tests in the present study includes cutoffs developed in a previous study $\left(\mathrm{SEBT}^{38}\right)$ and guidelines to evaluate a satisfactory result in functional performance tests (LSI for the 1-legged hop for distance, and side hop ${ }^{6,16}$ and tuck jump ${ }^{29}$ ). Cutoff scores were not available for the DVJ, and therefore scores from the highest tertile (valgus motion, side difference, and pKAM measured with DVJ) from our previous data including some of the same players (77 of the 117 players with ACLR and 77 of the 119 knee-healthy players ${ }^{10}$ ) were used. The 10 cutoffs for the 5 different tests and the definition of players with high-risk for new injury related to the specific tests are presented in Figure 1. 
The LSI was calculated for players with ACLR as (ACLR limb/uninvolved limb) $\times 100$ and for knee-healthy players as (nondominant limb/dominant limb) $\times 100$.

For the players with ACLR, 2 different LSI cutoffs were used for the 1-legged hop for distance, and side hop (i.e., $90 \%$ and $90 \%$ or $110 \%$ ). For the different cutoffs; (1) players with LSI $<90 \%$ and (2) players with $<90 \%$ and $>110 \%$ were defined as high-risk players for new injuries. For the knee-healthy players, $>10 \%$ side difference independent of which limb, i.e., an LSI of $<90 \%$ or $>110 \%$, was used. In addition, the number of players defined as high-risk according to the predefined cutoffs used in each of the 5 tests (SEBT; a composite score reach distance $\leq 94 \%$ of limb length, ${ }^{38}$ 1-legged hop for distance and side hop; an LSI of $<90 \%,{ }^{6,16}$ tuck jump $\geq 6$ flawed techniques; ${ }^{29}$ and DVJ; knee valgus motion $\geq 6.5 \mathrm{~cm}$ in any knee ${ }^{10}$ ) was also calculated. 


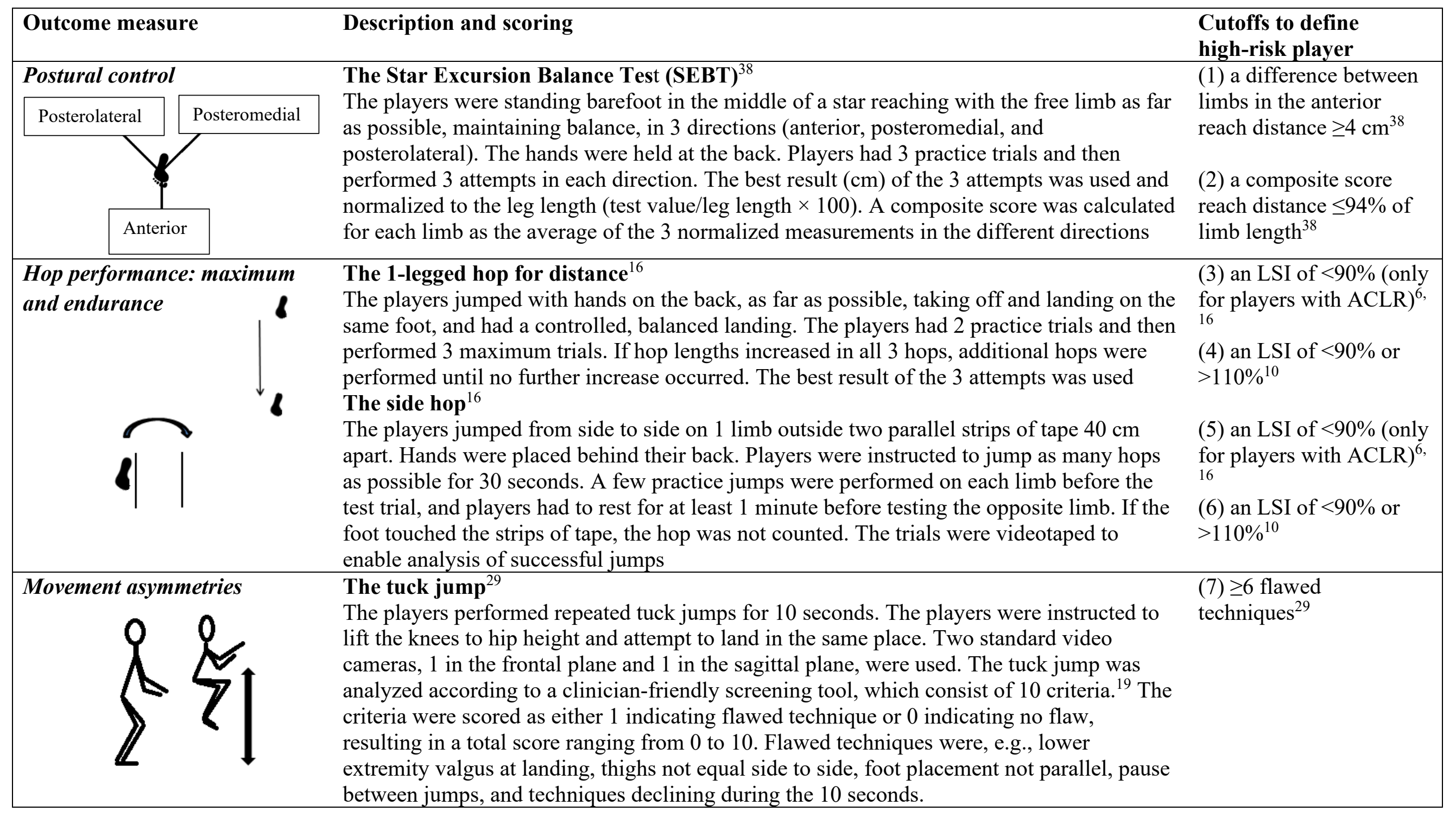




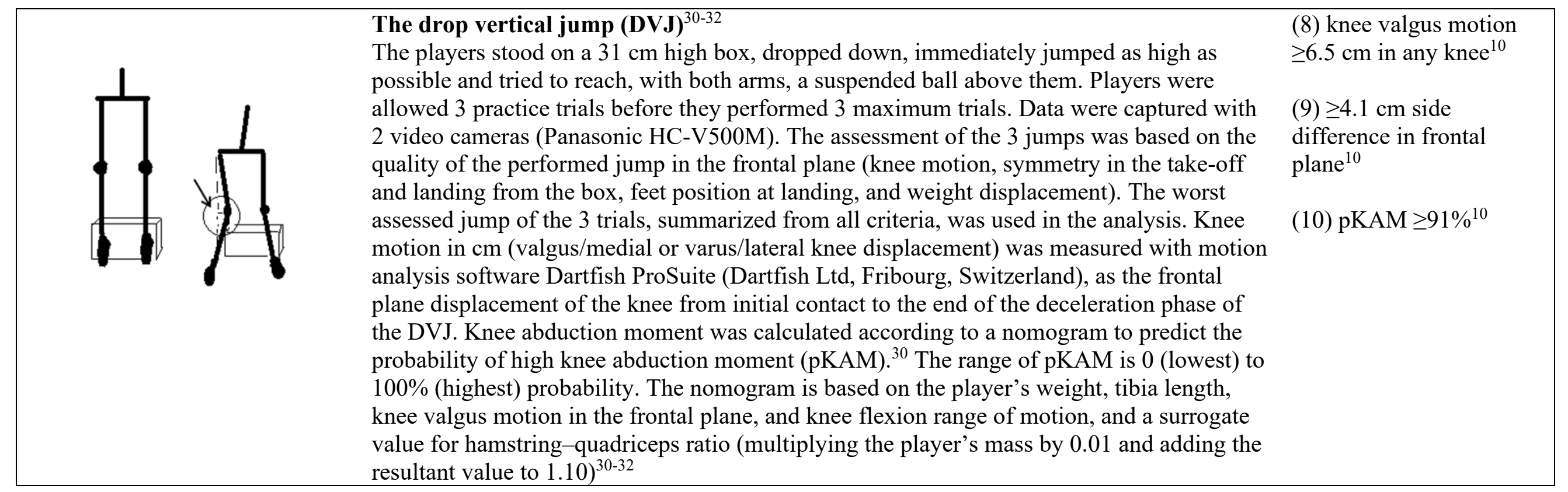

Figure 1. Description of the 5 functional performance tests with 10 different cutoffs, and the predefined definition of players with high-risk for new injury related to the specific tests and cutoffs. 


\section{Data Analysis}

2 All statistical analyses were performed with IBM SPSS Statistics for Windows (v 24.0;

$3 \quad$ IBM). Mean \pm standard deviation or median and interquartile range (IQR)/range were

4 calculated with descriptive statistics. Risk ratios (RR) and 95\% confidence intervals (CIs)

5 were calculated for (1) new ACL injuries and specifically ipsi- or contralateral ruptures in the

6 ACLR cohort, and (2) new other severe traumatic knee injuries, comparing the proportion of

7 players in a high-risk group (as determined by the predetermined cutoffs) with the proportion

8 of players in the referent group for each potential risk factor. The predictive validity of the

9 tests was assessed using receiver operating characteristic (ROC) curve statistics (area under

10 the curve [AUC]), and the sensitivity and specificity of the cutoffs. The definition of the AUC

11 was excellent $(0.90-1)$, good $(0.80-0.89)$, fair $(0.70-0.79)$, poor $(0.60-0.69)$, or fail $(<0.59)$.

12 The significance level was set at $P<.05$.

14 RESULTS

15 Forty-six players with ACLR (39\%) sustained 48 severe knee injuries, including 28 new

16 ACL injuries; 21 ipsilateral and 7 contralateral ruptures, during soccer. Of the knee-healthy

17 players, $13(11 \%)$ sustained 14 severe traumatic knee injuries including 8 ACL injuries (Table $181)^{11}$ 
Severe ( $>28$ Days Absence from Soccer Play) Traumatic Knee Injuries Reported from Baseline up to 2-Year Follow-Up in Players With ACL Reconstruction and Previously Knee-Healthy Players ${ }^{a}$

\begin{tabular}{|c|c|c|c|c|}
\hline & \multicolumn{2}{|c|}{$\begin{array}{l}\text { Players With ACL } \\
\text { Reconstruction } \\
(\mathrm{n}=117)\end{array}$} & \multicolumn{2}{|c|}{$\begin{array}{l}\text { Knee-Healthy Players } \\
\qquad(\mathrm{n}=119)\end{array}$} \\
\hline Total players with severe knee injury & \multicolumn{2}{|c|}{$46(39)$} & \multicolumn{2}{|c|}{$13(11)$} \\
\hline New ACL injuries ${ }^{b}$ & \multicolumn{2}{|c|}{$28(24)$} & \multicolumn{2}{|c|}{$8(7)$} \\
\hline \multirow[t]{2}{*}{ Other severe knee injuries ${ }^{b}$} & \multicolumn{2}{|c|}{$20(17)$} & \multicolumn{2}{|c|}{$6(5)$} \\
\hline & $\begin{array}{c}\mathrm{ACL} \\
\text { reconstructed } \\
\text { knee }\end{array}$ & $\begin{array}{c}\text { Contra- } \\
\text { lateral knee }\end{array}$ & $\begin{array}{c}\text { Non- } \\
\text { dominant } \\
\text { leg }\end{array}$ & $\begin{array}{l}\text { Dominant } \\
\text { leg }\end{array}$ \\
\hline \multicolumn{5}{|l|}{ No. of new severe traumatic knee injuries } \\
\hline ACL total rupture & $14^{c}$ & $7^{d}$ & $3^{e}$ & $4^{e}$ \\
\hline ACL partial rupture & $7^{f}$ & & & $1^{g}$ \\
\hline Meniscus lesion & $6^{e}$ & & $1^{g}$ & \\
\hline Cartilage lesion & $2^{h}$ & & & \\
\hline Medial or lateral collateral ligament injury & $2^{i}$ & $1^{i}$ & 2 & \\
\hline Patella subluxation & 1 & $1^{i}$ & & \\
\hline Joint sprain unspecified & 4 & & & \\
\hline Contusion & 1 & & 1 & $1^{i}$ \\
\hline Graft problems (fixation, scar tissue) & $2^{e}$ & & & \\
\hline Wound & & & 1 & \\
\hline
\end{tabular}

${ }^{a}$ Values are reported as $\mathrm{n}(\%)$. ACL, anterior cruciate ligament.

${ }^{b} 2$ players with ACL reconstruction reported 2 severe knee injuries. 1 further ACL re-rupture occurred when skiing and was not included in the analysis; 1 player in the knee-healthy cohort had 2 severe knee injuries.

${ }^{c} 12$ surgically diagnosed/treated, 1 diagnosed with magnetic resonance imaging, and 1 clinically.

${ }^{d} 6$ surgically diagnosed/treated, 1 diagnosed with magnetic resonance imaging.

${ }^{e}$ All surgically treated.

$f_{5}$ surgically diagnosed/treated, 2 diagnosed clinically.

${ }^{g} 1$ surgically diagnosed/treated.

${ }^{h} 1$ surgically diagnosed/treated, 1 diagnosed with magnetic resonance imaging.

${ }^{i} 1$ diagnosed with magnetic resonance imaging.

\section{Functional performance Tests}

Scores, LSI values, and the number of players with functional performance test results with ACLR and $14 \%$ to $61 \%$ for knee-healthy players (Table 2). 
TABLE 2

Scores, LSI Values, and the Numbers of Players Defined as High-risk According to the Predefined Cutoffs in the Different Functional Performance Tests for the Reconstructed and Uninvolved Limbs of Female Soccer Players

With ACLR and the Nondominant and Dominant Limbs of Knee-Healthy Players ${ }^{a}$

\begin{tabular}{|c|c|c|c|c|c|}
\hline \multirow[t]{2}{*}{ Test } & \multicolumn{2}{|c|}{ Players With ACLR $(n=117)$} & \multicolumn{3}{|c|}{ Knee-Healthy Players $(\mathrm{n}=119)$} \\
\hline & $\begin{array}{l}\text { No new ACL } \\
\text { injury }(n=89)\end{array}$ & $\begin{array}{c}\text { New ACL injury } \\
\quad(n=28)\end{array}$ & & $\begin{array}{l}\text { No ACL injury } \\
\quad(n=111)\end{array}$ & $\begin{array}{l}\text { ACL injury } \\
(\mathrm{n}=8)\end{array}$ \\
\hline \multicolumn{6}{|c|}{ Star Excursion Balance Test - anterior reach distance, $\%^{b}$} \\
\hline ACLR limb & $84 \pm 6$ & $83 \pm 6$ & Nondominant limb & $85 \pm 6$ & $87 \pm 3$ \\
\hline Uninvolved limb & $85 \pm 6$ & $83 \pm 7$ & Dominant limb & $84 \pm 6$ & $86 \pm 2$ \\
\hline $\mathrm{LSI}^{c}$ & $99 \pm 3$ & $101 \pm 3$ & & $101 \pm 3$ & $101 \pm 3$ \\
\hline Side difference $\geq 4 \mathrm{~cm}$ & $14(16)$ & $1(4)$ & & $16(14)$ & $1(13)$ \\
\hline \multicolumn{6}{|c|}{ Star Excursion Balance Test - composite score, $\%^{b}$} \\
\hline ACLR limb & $92 \pm 6$ & $92 \pm 7$ & Nondominant limb & $93 \pm 5$ & $95 \pm 3$ \\
\hline Uninvolved limb & $93 \pm 6$ & $92 \pm 6$ & Dominant limb & $93 \pm 6$ & $95 \pm 2$ \\
\hline $\mathrm{LSI}^{c}$ & $100 \pm 3$ & $100 \pm 2$ & & $101 \pm 3$ & $100 \pm 2$ \\
\hline$\leq 94 \%$ of limb length & $59(66)$ & $17(61)$ & & $68(61)$ & $4(50)$ \\
\hline \multicolumn{6}{|l|}{ 1-legged hop for distance, $\mathrm{cm}$} \\
\hline ACLR limb & $120 \pm 19$ & $127 \pm 23$ & Nondominant limb & $125 \pm 17$ & $140 \pm 13$ \\
\hline Uninvolved limb & $122 \pm 18$ & $128 \pm 21$ & Dominant limb & $124 \pm 18$ & $139 \pm 18$ \\
\hline $\mathrm{LSI}^{c}$ & $98 \pm 8$ & $98 \pm 9$ & & $101 \pm 8$ & $101 \pm 7$ \\
\hline $\mathrm{LSI}^{c}<90 \%$ & $12(13)$ & $3(11)$ & & n.a. & n.a. \\
\hline $\mathrm{LSI}^{c}<90 \%$ or $>110 \%$ & $17(19)$ & $6(21)$ & & $18(16)$ & $1(13)$ \\
\hline \multicolumn{6}{|l|}{ Side hop, $\mathrm{n}$} \\
\hline ACLR limb & $32 \pm 14$ & $41 \pm 17$ & Nondominant limb & $37 \pm 14$ & $49 \pm 11$ \\
\hline Uninvolved limb & $36 \pm 13$ & $42 \pm 15$ & Dominant limb & $38 \pm 13$ & $48 \pm 12$ \\
\hline $\mathrm{LSI}^{c}$ & $92 \pm 22$ & $98 \pm 19$ & & $98 \pm 17$ & $105 \pm 15$ \\
\hline $\mathrm{LSI}^{c}<90 \%$ & $36(40)$ & $6(21)$ & & n.a. & n.a. \\
\hline $\mathrm{LSI}^{c}<90 \%$ or $>110 \%$ & $50(56)$ & $11(39)$ & & $46(41)$ & $3(38)$ \\
\hline Tuck jump, total score $(0-10)$ & $5 \pm 2$ & $5 \pm 2$ & & $5 \pm 2$ & $4 \pm 1.5$ \\
\hline$\geq 6$ flawed techniques & $38(43)$ & $12(43)$ & & $36(32)$ & $1(13)$ \\
\hline \multicolumn{6}{|c|}{ Drop vertical jump, knee motion in frontal plane $(\mathrm{cm})^{d}$} \\
\hline ACLR limb & $3(4 ;-8$ to 9$)$ & $3(6 ;-3$ to 11$)$ & Nondominant limb & $5(4 ;-5$ to 17$)$ & $7(4 ; 0-11)$ \\
\hline Uninvolved limb & $3(6 ;-10$ to 11$)$ & $4(4 ;-1$ to 9.0 & Dominant limb & $4(4 ;-7$ to 13$)$ & $4(7 ; 0-9)$ \\
\hline$\geq 6.5 \mathrm{~cm}$ valgus in any knee & $21(24)$ & $8(29)$ & & $40(36)$ & $6(75)$ \\
\hline$\geq 4.1 \mathrm{~cm}$ side difference & $28(31)$ & $12(43)$ & & $33(30)$ & $3(38)$ \\
\hline \multicolumn{6}{|c|}{ Probability of a high knee abduction moment, pKAM (\%) } \\
\hline ACLR limb & $67(40 ; 10-98)$ & $60(46 ; 14-99)$ & Nondominant limb & $78(12 ; 7-100)$ & $86(19 ; 40-99)$ \\
\hline Uninvolved limb & $71(37 ; 15-98)$ & $67(40 ; 21-96)$ & Dominant limb & $70(44 ; 7.4-98.7)$ & $71(50 ; 13-95)$ \\
\hline $\mathrm{pKAM} \geq 91 \%$ & $21(24)$ & $7(25)$ & & $38(34)$ & $4(50)$ \\
\hline
\end{tabular}

${ }^{a}$ Values are reported as means \pm SD, medians (interquartile range; range), or $\mathrm{n}(\%)$. ACLR, anterior cruciate ligament reconstruction; LSI, limb symmetry index; n.a., not applicable.

${ }^{b}$ Reach distance in centimeters was normalized to the leg length ([test value/leg length] $\times 100$ ). The composite score is the average of the 3 normalized measurements in the different directions.

${ }^{c}$ LSI was calculated as $(\mathrm{ACL}-$ reconstructed limb/uninvolved limb) $\times 100$ or (nondominant limb/dominant limb) $\times 100$.

${ }^{d}$ Positive values refers to valgus (medial) motion; negative values refers to varus (lateral) motion.

\section{Validation of Predetermined Cutoffs}

\section{Prediction of New ACL Injury}


significant associations between predetermined cutoffs on any of the tests and the risk of sustaining an additional ACL injury in players with ACLR. In knee-healthy players, the only variable associated with new ACL injury was $\geq 6.5 \mathrm{~cm}$ knee valgus in the frontal plane (in any knee) in the DVJ (RR, 4.93; 95\% CI, 1.04-23.40; $P=.045)$, but with only fair predictive validity $(A U C=0.7$, sensitivity $=0.75$, specificity $=0.65)$ (Figure 4$)$. Six of the 46 knee-healthy players that had $\geq 6.5 \mathrm{~cm}$ valgus in any knee in the DVJ and who sustained an ACL injury during follow-up had $\geq 6.5 \mathrm{~cm}$ in their nondominant limb, and 2 also had $>6.5 \mathrm{~cm}$ valgus in their dominant limb. All new ACL injuries occurred in the dominant limb except in one player (valgus $\geq 6.5 \mathrm{~cm}$ in both limbs).

Separate analyses of association between cutoffs in the 5 different functional tests and risk of sustaining a rerupture or contralateral rupture specifically showed that the risk for a contralateral rupture was almost 5 times higher with a side difference in valgus $\geq 4.1 \mathrm{~cm}$ (AUC $=0.8,71 \%$ sensitivity and $69 \%$ specificity), but did not reach statistical significance (RR, 4.813; 95\% CI, 0.977-23.711; $P=.053$ ) (Supplemental Appendix, Figure 9c).
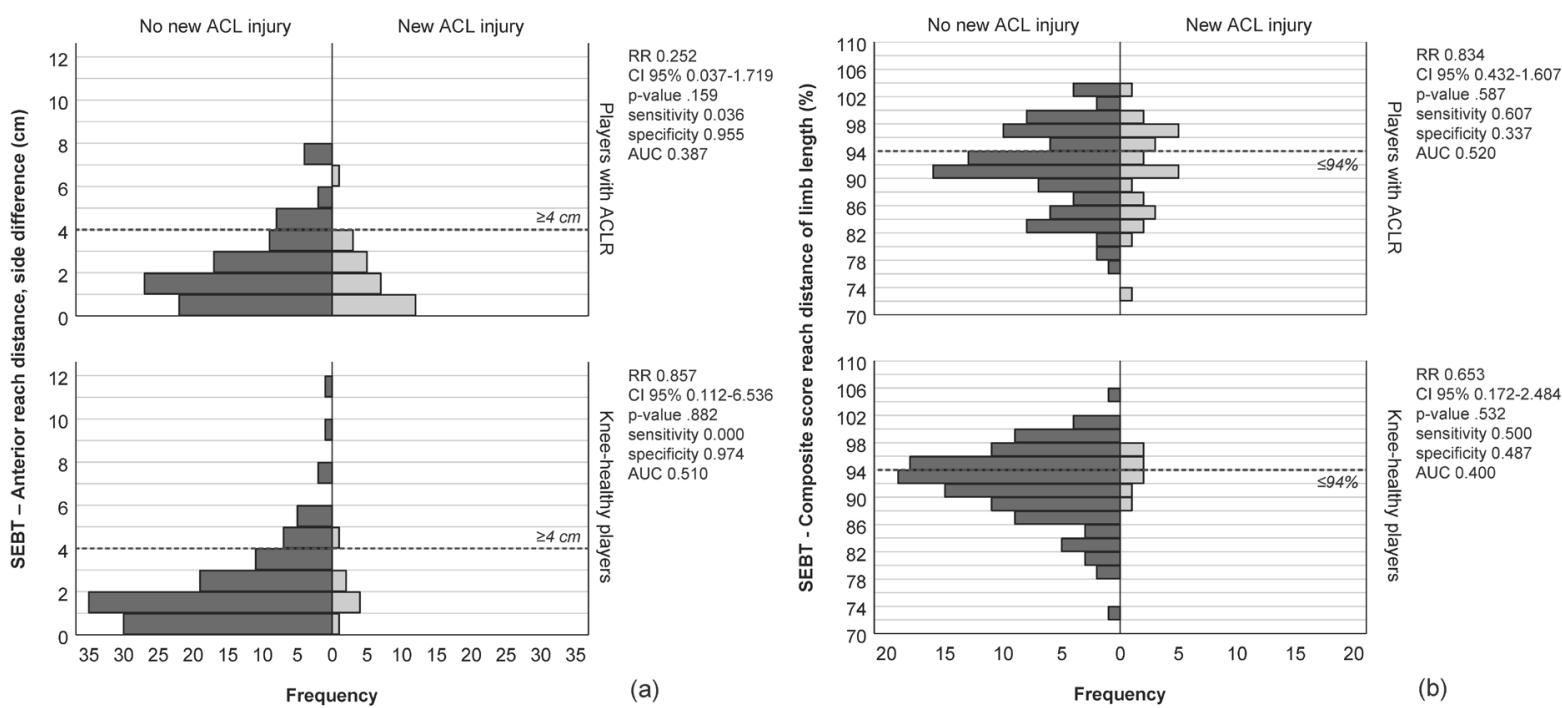

Figure 2. Postural control: risk ratio (RR), 95\% confidence interval (CI), $P$ value for the 2 cohorts, players with ACLR and knee-healthy players, comparing the proportion of 
players with cutoffs defining a high or low-risk player, and sustaining a new ACL injury: (a) $\geq 4 \mathrm{~cm}$ side difference in anterior reach distance and (b) $\leq 94 \%$ of limb length in composite score in the Star Excursion Balance Test (SEBT). The predictive validity of the cutoffs was assessed with receiver operating characteristic curve statistics with area under the curve (AUC), sensitivity, and specificity.
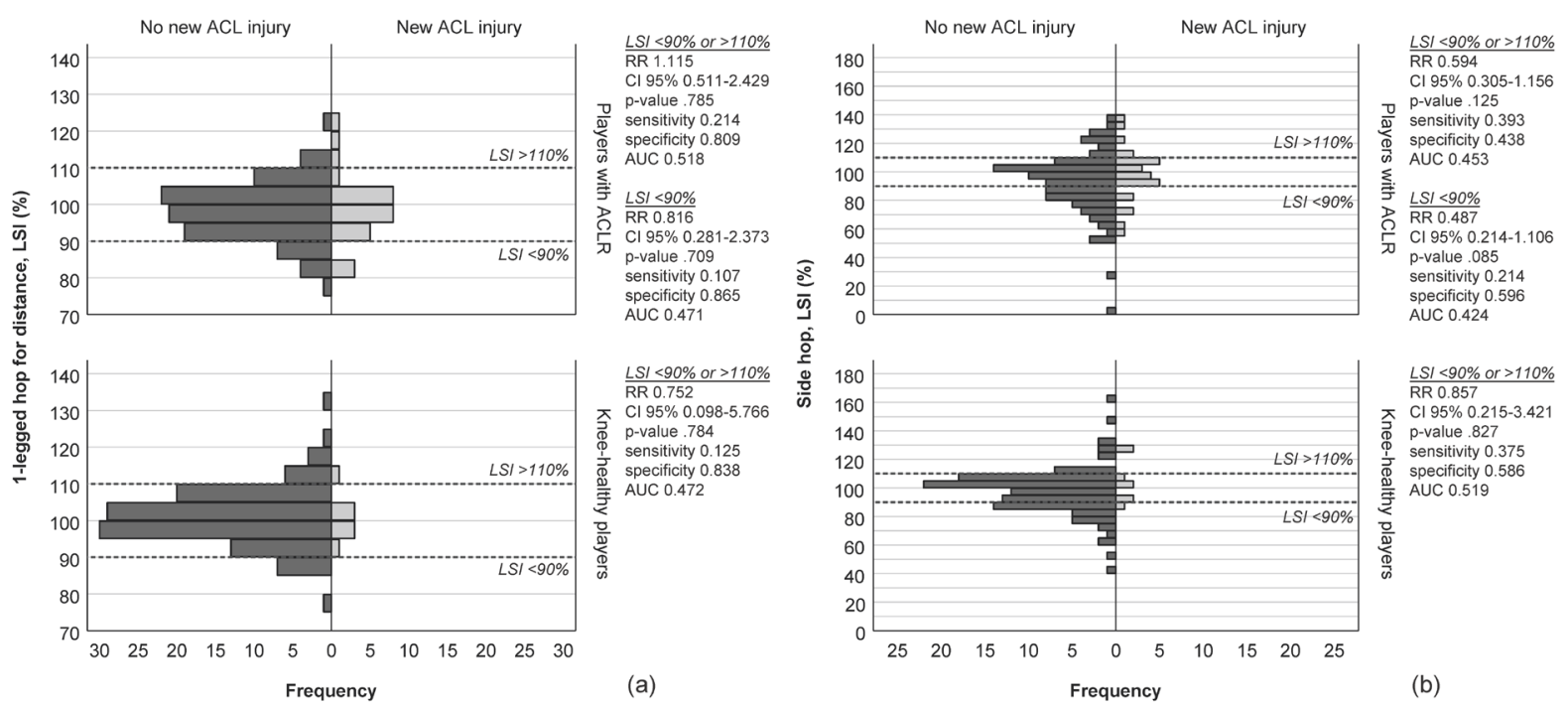

Figure 3. Hop performance: risk ratio (RR), $95 \%$ confidence interval (CI), $P$ value for the 2 cohorts, players with ACLR and knee-healthy players, comparing the proportion of players with cutoffs defining a high or low-risk player, and sustaining a new ACL injury: (1) Limb Symmetry Index (LSI) $<90 \%$, (2) $<90 \%$ or $>110 \%$, i.e., the ACLR limb should neither not be $10 \%$ weaker or stronger compared with the nonreconstructed leg in (a) 1-legged hop for distance and (b) side hop. The predictive validity of the cutoffs was assessed with receiver operating characteristic curve statistics with area under the curve (AUC), sensitivity, and specificity. 

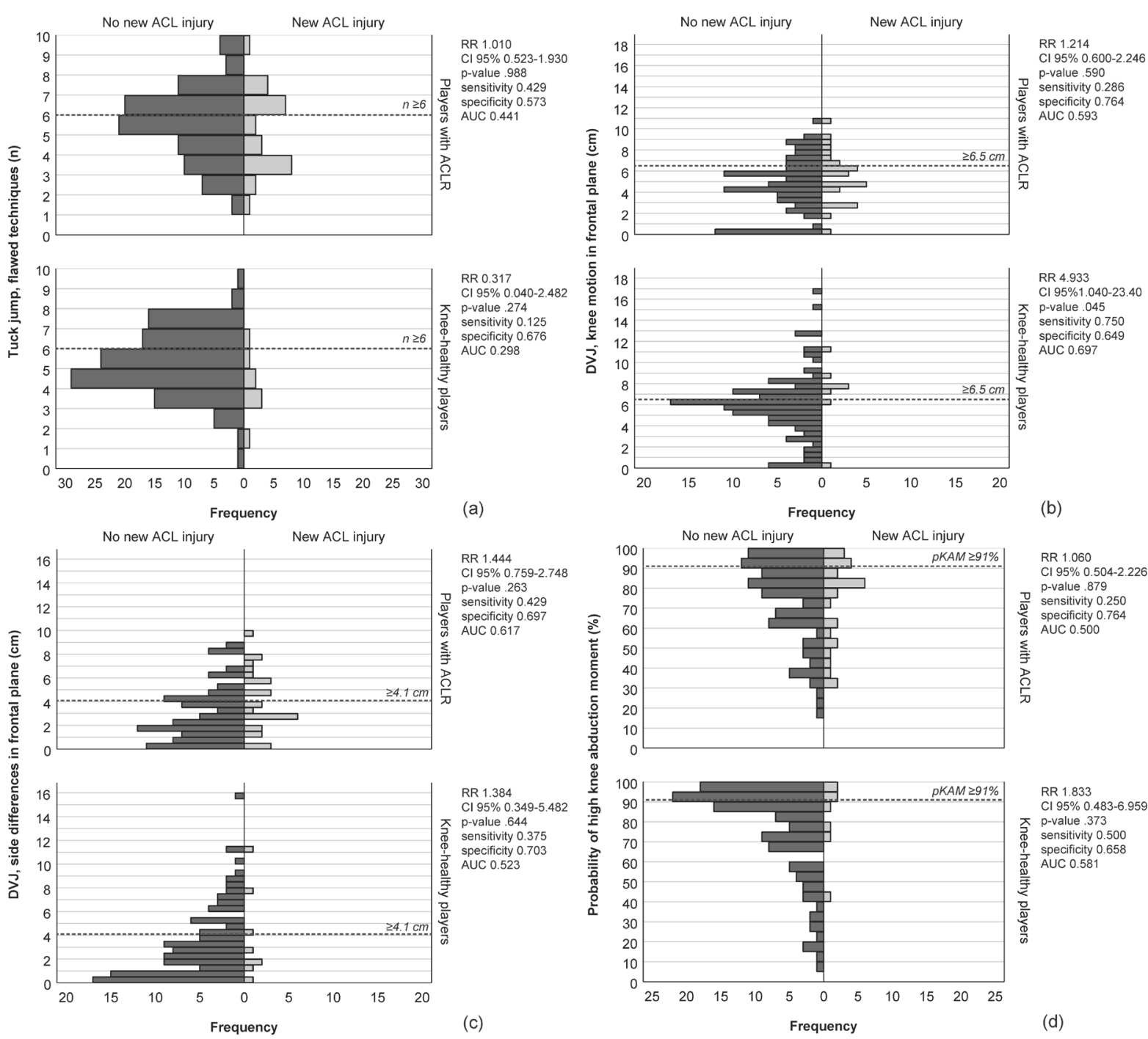

Figure 4. Movement asymmetries in the lower limbs and trunk: risk ratio (RR), 95\% confidence interval (CI), $P$ value for the 2 cohorts, players with ACLR and kneehealthy players, comparing the proportion of players with cutoffs defining a high or low-risk player, and sustaining a new ACL injury; (a) $\geq 6$ flawed techniques in the tuck jump, (b) knee valgus motion $\geq 6.5 \mathrm{~cm}$ in any knee, (c) $\geq 4.1 \mathrm{~cm}$ side difference in frontal plane, (d) probability of high knee abduction moment (pKAM) $\geq 91 \%$ in drop vertical jump (DVJ) and sustaining a new ACL injury. The predictive validity of the cutoffs was assessed with receiver operating characteristic curve statistics with area under the curve (AUC), sensitivity, and specificity. 


\section{Prediction of New Severe Traumatic Knee Injury}

There was no significant association between predetermined cutoffs for the different tests and risk of sustaining a severe traumatic knee injury in players with ACLR or in knee-healthy players (Supplemental Appendix, Figures 1-3).

\section{Numbers of Players Who Had Predefined Cutoffs Defining a High-Risk Player in Each}

\section{of the 5 Tests}

Overall, only $9 \%$ of the players with ACLR (10 of 117) and 8\% of the knee-healthy players (9 of 119) were classified as a low-risk players based on all 5 predetermined cutoffs in the test battery. There was no difference in the risk of new ACL injury between players who were classified as high-risk players according to the 5 predetermined cutoffs and those who did not, neither in players with ACLR (RR, 0.561; 95\% CI, 0.243-1.295; $P=.176)$ nor in knee-healthy players (RR, $0.573 ; 95 \% \mathrm{CI}, 0.079-4.157 ; P=.582)$. Similarly, there was no difference in the risk of other severe knee injury in players with ACLR (RR, 0.623; 95\% CI, 0.355-1.093; $P=.099)$ or knee-healthy players (RR, $0.981 ; 95 \% \mathrm{CI}, 0.143-6.720 ; P=.985)$.

\section{DISCUSSION}

The main finding was that none of the 10 cutoffs in the 5 different functional performance tests had any predictive validity for new knee injuries in the ACLR cohort. In knee-healthy players, only 1 cutoff from 1 functional performance test (knee valgus $\geq 6.5 \mathrm{~cm}$ in any knee in the frontal plane measured during DVJ) showed an association with a 5 times higher risk of sustaining an ACL injury, but only with fair combined sensitivity and specificity. Thus, the predetermined cutoffs evaluated in this study has questionable value in identifying risk factors and helping clinicians in the goal of preventing a severe knee injury in female soccer players. 
The cutoffs used for postural control measures, i.e., SEBT, have previously been described by Plisky et al. ${ }^{38}$ They reported an association between (1) side-to-side differences in the anterior reach distance, and (2) a composite score reach distance $\leq 94 \%$ of limb length, and risk of injury to the lower extremities in high school basketball players. These results could not be confirmed in our cohorts regarding severe knee injuries, and further validation of the

124 SEBT and these 2 cutoffs is needed.

125 The cutoffs of an LSI $<90 \%$, defining a high-risk player, used for the 1-legged hop for distance and side hop did not show any association with sustaining a severe knee injury. The most commonly used cutoff for hop performance tests, ${ }^{41}$ is an LSI of $90 \% .{ }^{6,44}$ There is, to our knowledge, only 1 study showing any relationship with reaching an LSI $\geq 90 \%$ and sustaining fewer knee injuries. Grindem et $\mathrm{al}^{15}$ showed that reaching an LSI $\geq 90 \%$ in

130 quadriceps strength before return to sport after ACLR was associated with a lower knee 131 reinjury rate, but, in line with our results, this association was not reported for the 1-legged 132 hop for distance, $6 \mathrm{~m}$ timed hop, triple hop for distance, and cross-over hop for distance.

133 However, the validity of the specific LSI cutoffs in different hop performance tests for 134 evaluating the risk of sustaining an injury has been questioned. ${ }^{41,46}$ LSI can overestimate 135 performance due to bilateral deficits and poor performance of the non-ACLR limb. ${ }^{13,46}$ The 136 cutoff is sometimes proposed to be $100 \%$ of LSI as a more precise and demanding criteria for 137 athletes who will return to cutting and pivoting sports. ${ }^{41}$ On the other hand, there is a 3 times 138 increased risk for contralateral ruptures in athletes with ACLR who passed return-to-sport

139 criteria. ${ }^{44}$ A hypothesis is that side-to-side asymmetries may increase injury risk to both 140 limbs. ${ }^{37}$ Therefore, a cutoff of an LSI of $>110 \%$, defining a high-risk player, was also 141 analyzed in the cohort of players with ACLR. However, asymmetries indicating stronger 142 ACLR leg (LSI $>110 \%$ ) were not associated with sustaining a secondary knee injury. 
The results in our study did not show any association between $<6$ flawed techniques in the

144 tuck jump and sustaining a primary or secondary knee injury. The cutoff of 6 or more flaws

145 during the tuck jump is based on empirical evidence and is associated with poor performance,

146 identifying players who might be at risk for ACL injury. ${ }^{2,}{ }^{29}$ However, no relationship was

147 reported between tuck jump assessment and knee valgus measured with DVJ, one-legged hop

148 for distance, the International Knee Documentation Committee 2000 Subjective Knee Form

149 and the Knee injury Osteoarthritis Outcome Score. ${ }^{2}$ Still, this cutoff has not been previously

150 validated, and the test need further validation. ${ }^{2,8}$ It may be more valuable clinically to use the

151 individual tuck jump assessment items than assessing the total score. ${ }^{2}$

152 We found no association between movement asymmetries in the DVJ and a secondary knee

153 injury. Only 1 of 3 cutoffs ( $\geq 6.5 \mathrm{~cm}$ knee valgus in any knee in frontal plane) showed an

154 association with primary ACL injury, albeit only with fair combined sensitivity and

155 specificity. Our hypothesis was that knee valgus $\geq 6.5 \mathrm{~cm}$ in any knee could represent

156 movement asymmetries associated with an increased risk for a new knee injury in that athlete.

157 This is supported by the fact that Hewett et $\mathrm{al}^{20}$ reported that ACL-injured females had 6.4

158 times greater side-to-side knee abduction moment difference in DVJ test compared to

159 uninjured females.

160 There are conflicting results and limited evidence on whether knee valgus motion, as a part

161 of movement asymmetries evaluation, is associated with an increased risk of sustaining a

162 primary or secondary ACL injury. For primary injury prediction, Hewett et a ${ }^{20}$ reported that

163 increased dynamic valgus and high abduction loads in female athletes could predict an ACL

164 injury with $78 \%$ sensitivity and $73 \%$ specificity. In contrast, Goetschius et al ${ }^{12}$ and Krosshaug

165 et $\mathrm{al}^{23}$ did not show that high valgus motion was predictive for sustaining an ACL injury for

166 previously uninjured female athletes. For secondary injury prediction, some associations with

167 increased knee valgus pattern during a DVJ and sustaining an ACL re-injury have been 
168 reported..$^{23,37}$ In addition, many ACL injury prevention programs that have been proven to

169 decrease primary ACL injuries by $53 \%{ }^{21}$ target movement asymmetries, such as avoiding

170 knee valgus motion and using proper landing mechanics. ${ }^{21}$ Still, the cause in relation to

171 prevention in these programs is still unknown, ${ }^{40}$ and the predictive value of dynamic knee

172 valgus motion pattern for a primary and secondary ACL injury is still not confirmed.

173 Our results showed that analyzing all tests as a test battery, i.e., players who were defined

174 as high-risk players in each of the 5 tests, was not associated with an increased risk of new

175 ACL injury or severe knee injury. These results are in line with most of the previous studies

176 evaluating different test batteries, mainly including strength and hop performance tests. ${ }^{5,27,44 \text {, }}$

$177 \quad{ }^{45}$ However, 2 previous studies found an association between results in test batteries and

178 sustaining a second ACL injury, but each test alone in the test batteries did not predict a

179 second ACL injury. ${ }^{25,43}$ Although there is no objective criteria, ${ }^{17}$ or test after an ACLR that

180 can predict who will sustain a new injury, ${ }^{18}$ it is considered best approach to evaluate different

181 components and use a battery of tests to inform the return-to-sport decision. ${ }^{1,25,41}$ Test

182 batteries also discriminate better between involved and uninvolved limbs than single tests. ${ }^{16,41}$

183 In our study, only $9 \%$ of the players with ACLR and $8 \%$ of knee-healthy players were

184 classified as low-risk players based on all 5 tests. This is in line with previous studies showing 185 that only $11 \%-23 \%$ of the athletes with $\operatorname{ACLR}^{10,44,45}$ and $19 \%$ of knee-healthy players passed

186 all criteria in test batteries. ${ }^{10}$ The likelihood of passing a full test battery is dependent on the

187 number of tests used and the cutoffs, the more tests and cutoffs included, the more difficult it

188 is for patients to pass the full test battery. ${ }^{44}$ Therefore, how many and which tests and cutoffs

189 should be included in a test battery requires further evaluation.

190 Another question is whether the functional performance tests commonly used in clinic

191 capture the risk factors related to common knee injury mechanisms. The drop vertical jump

192 and tuck jump tests both aim to capture the valgus mechanism involved in many non-contact 
193 and indirect contact ACL injuries in soccer. ${ }^{7,42}$ It is possible that more soccer-specific

194 functional tests should be used, but these are often more difficult to standardize and to

195 perform in many clinics because of limited space. The used cutoffs for the different tests

196 could also be inappropriate, but in our data no other cutoff could be used to predict a new

197 ACL or severe knee injury.

198 Our results showed that commonly used functional performance tests did not predict new

199 severe knee injuries. However, functional testing of players and patients is positive in many

200 aspects because these give valuable information about the players' progress in the

201 rehabilitation after injury, identify deficits, for goalsetting, feedback, and engagement with

202 the medical team for each player. ${ }^{33}$

203 A strength of the present study is the homogeneous cohort of female soccer players with

204 ACLR and knee-healthy players from the same soccer teams. Another strength is the

205 prospective design of the data collection with relatively frequent follow-up to reduce the risk

206 of recall bias. All severe knee injuries were also verified from medical charts. Some

207 limitations other than the ones already discussed should be acknowledged. We were not aware

208 of the amount of match or training soccer exposure, and this is probably the most important

209 risk factor for new injury. Hypothetically, players who do not meet the cutoffs and have

210 worse performance could have less soccer exposure with less stress and forces on the knee

211 and thus be less likely to sustain a new injury, and vice versa. To evaluate tests to predict

212 injuries in future the risk exposure for the athletes is important.

\section{CONCLUSIONS}

214 Previously predetermined cutoffs used to differentiate between high and low-risk players

215 on commonly used functional tests to assess postural control, hop performance, and

216 movement asymmetries in the lower limbs and trunk showed poor validity to predict new 
knee injuries in female soccer players. Ten cutoffs for 5 functional tests in two different

218 cohorts of female soccer players were tested, and the predictive validity for both cohorts in

219 players with a previous ACLR and in previously knee-healthy players was poor.

\section{REFERENCES}

1. Ardern CL, Glasgow P, Schneiders A, et al. 2016 Consensus statement on return to sport from the First World Congress in Sports Physical Therapy, Bern. Br J Sports Med. 2016;50(14):853-864. PMID: 27226389.

2. Arundale AJH, Kvist J, Hägglund M, Fältström A. Tuck jump score is not related to hopping performance or patient-reported outcome measures in female soccer players Int J Sports Phys Ther. 2020;15(3):395-406. PMID: 32566376.

3. Bahr R. Why screening tests to predict injury do not work-and probably never will...: a critical review. Br J Sports Med. 2016;50(13):776-780. PMID: 27095747.

4. Bakken A, Targett S, Bere T, et al. The functional movement test 9+ is a poor screening test for lower extremity injuries in professional male football players: a 2year prospective cohort study. Br J Sports Med. 2018;52(16):1047-1053. PMID: 28512188.

5. Beischer S, Gustavsson L, Senorski EH, et al. Young Athletes Who Return to Sport Before 9 Months After Anterior Cruciate Ligament Reconstruction Have a Rate of New Injury 7 Times That of Those Who Delay Return. J Orthop Sports Phys Ther. 2020;50(2):83-90. PMID: 32005095.

6. Burgi CR, Peters S, Ardern CL, et al. Which criteria are used to clear patients to return to sport after primary ACL reconstruction? A scoping review. Br J Sports Med. 2019;53(18):1154-1161. PMID: 30712009.

7. Della Villa F, Buckthorpe M, Grassi A, et al. Systematic video analysis of ACL injuries in professional male football (soccer): injury mechanisms, situational patterns and biomechanics study on 134 consecutive cases. Br J Sports Med. 2020. PMID: 32561515 .

8. Fox AS, Bonacci J, McLean SG, Spittle M, Saunders N. A Systematic Evaluation of Field-Based Screening Methods for the Assessment of Anterior Cruciate Ligament (ACL) Injury Risk. Sports Med. 2016;46(5):715-735. PMID: 26626070.

9. Fuller CW, Ekstrand J, Junge A, et al. Consensus statement on injury definitions and data collection procedures in studies of football (soccer) injuries. Clin J Sport Med. 2006;16(2):97-106. PMID: 16603877 
10. Fältström A, Hägglund M, Kvist J. Functional performance among active female soccer players after unilateral primary anterior cruciate ligament reconstruction compared with knee-healthy controls. Am J Sports Med. 2017;45(2):377-385. PMID: 28146394.

11. Fältström A, Kvist J, Gauffin H, Hägglund M. Female soccer players with anterior cruciate ligament reconstruction have a higher risk of new knee injuries and quit soccer to a higher degree than knee-healthy controls. Am J Sports Med. 2019;47(1):3140. PMID: 30481050.

12. Goetschius J, Smith HC, Vacek PM, et al. Application of a clinic-based algorithm as a tool to identify female athletes at risk for anterior cruciate ligament injury: a prospective cohort study with a nested, matched case-control analysis. Am J Sports Med. 2012;40(9):1978-1984. PMID:22879400.

13. Gokeler A, Welling W, Benjaminse A, Lemmink K, Seil R, Zaffagnini S. A critical analysis of limb symmetry indices of hop tests in athletes after anterior cruciate ligament reconstruction: A case control study. Orthop Traumatol Surg Res. 2017;103(6):947-951. PMID: 28428033.

14. Graziano J, Chiaia T, de Mille P, Nawabi DH, Green DW, Cordasco FA. Return to Sport for Skeletally Immature Athletes After ACL Reconstruction: Preventing a Second Injury Using a Quality of Movement Assessment and Quantitative Measures to Address Modifiable Risk Factors. Orthop J Sports Med. 2017;5(4):2325967117700599. PMID: 28451617.

15. Grindem H, Snyder-Mackler L, Moksnes H, Engebretsen L, Risberg MA. Simple decision rules can reduce reinjury risk by $84 \%$ after ACL reconstruction: the Delaware-Oslo ACL cohort study. Br J Sports Med. 2016;50(13):804-808. PMID: 27162233

16. Gustavsson A, Neeter C, Thomée P, et al. A test battery for evaluating hop performance in patients with an ACL injury and patients who have undergone ACL reconstruction. Knee Surg Sports Traumatol Arthrosc. 2006;14(8):778-788. PMID:16525796.

17. Harris JD, Abrams GD, Bach BR, et al. Return to sport after ACL reconstruction. Orthopedics. 2014;37(2):e103-108. PMID:24679194.

18. Hegedus EJ, McDonough S, Bleakley C, Cook CE, Baxter GD. Clinician-friendly lower extremity physical performance measures in athletes: a systematic review of measurement properties and correlation with injury, part 1 . The tests for knee function including the hop tests. Br J Sports Med. 2015;49(10):642-648. PMID: 25497489.

19. Herrington L, Myer GD, Munro A. Intra and inter-tester reliability of the tuck jump assessment. Phys Ther Sport. 2013;14(3):152-155. PMID:23084318.

20. Hewett TE, Myer GD, Ford KR, et al. Biomechanical measures of neuromuscular control and valgus loading of the knee predict anterior cruciate ligament injury risk in female athletes: a prospective study. Am J Sports Med. 2005;33(4):492-501. PMID: 15722287. 
21. Huang YL, Jung J, Mulligan CMS, Oh J, Norcross MF. A Majority of Anterior Cruciate Ligament Injuries Can Be Prevented by Injury Prevention Programs: A Systematic Review of Randomized Controlled Trials and Cluster-Randomized Controlled Trials With Meta-analysis. Am J Sports Med. 2019:363546519870175. PMID: 31469584.

22. Ithurburn MP, Longfellow MA, Thomas S, Paterno MV, Schmitt LC. Knee Function, Strength, and Resumption of Preinjury Sports Participation in Young Athletes Following Anterior Cruciate Ligament Reconstruction. J Orthop Sports Phys Ther. 2019;49(3):145-153. PMID: 30770031.

23. Krosshaug T, Steffen K, Kristianslund E, et al. The vertical drop jump is a poor screening test for ACL injuries in female elite soccer and handball players: A prospective cohort study of 710 athletes. Am J Sports Med. 2016;44(4):874-883. PMID: 26867936.

24. Kvist J, Kartus J, Karlsson J, Forssblad M. Results from the Swedish national anterior cruciate ligament register. Arthroscopy. 2014;30(7):803-810. PMID:24746404.

25. Kyritsis $\mathrm{P}$, Bahr R, Landreau P, Miladi R, Witvrouw E. Likelihood of ACL graft rupture: not meeting six clinical discharge criteria before return to sport is associated with a four times greater risk of rupture. Br J Sports Med. 2016;50(15):946-951. PMID: 27215935.

26. Leppänen M, Pasanen K, Kujala UM, et al. Stiff Landings Are Associated With Increased ACL Injury Risk in Young Female Basketball and Floorball Players. Am J Sports Med. 2017;45(2):386-393. PMID: 28272935.

27. Losciale JM, Zdeb RM, Ledbetter L, Reiman MP, Sell TC. The Association Between Passing Return-to-Sport Criteria and Second Anterior Cruciate Ligament Injury Risk: A Systematic Review With Meta-Analysis. J Orthop Sports Phys Ther. 2018:1-52. PMID: 30501385

28. McCall A, Carling C, Davison M, et al. Injury risk factors, screening tests and preventative strategies: a systematic review of the evidence that underpins the perceptions and practices of 44 football (soccer) teams from various premier leagues. Br J Sports Med. 2015;49(9):583-589. PMID: 25576530.

29. Myer GD, Ford KR, Hewett TE. Tuck Jump Assessment for Reducing Anterior Cruciate Ligament Injury Risk. Athl Ther Today. 2008;13(5):39-44. PMID:19936042.

30. Myer GD, Ford KR, Hewett TE. New method to identify athletes at high risk of ACL injury using clinic-based measurements and freeware computer analysis. Br J Sports Med. 2011;45(4):238-244. PMID:21081640.

31. Myer GD, Ford KR, Khoury J, Succop P, Hewett TE. Clinical correlates to laboratory measures for use in non-contact anterior cruciate ligament injury risk prediction algorithm. Clin Biomech (Bristol, Avon). 2010;25(7):693-699. PMID:20554101.

32. Myer GD, Ford KR, Khoury J, Succop P, Hewett TE. Development and validation of a clinic-based prediction tool to identify female athletes at high risk for anterior cruciate ligament injury. Am J Sports Med. 2010;38(10):2025-2033. PMID:20595554. 
33. Myer GD, Paterno MV, Ford KR, Hewett TE. Neuromuscular training techniques to target deficits before return to sport after anterior cruciate ligament reconstruction. $J$ Strength Cond Res. 2008;22(3):987-1014. PMID: 18438211.

34. Nawasreh Z, Logerstedt D, Cummer K, Axe MJ, Risberg MA, Snyder-Mackler L. Do Patients Failing Return-to-Activity Criteria at 6 Months After Anterior Cruciate Ligament Reconstruction Continue Demonstrating Deficits at 2 Years? Am J Sports Med. 2017;45(5):1037-1048. PMID: 28125899.

35. Nilstad A, Andersen TE, Bahr R, Holme I, Steffen K. Risk factors for lower extremity injuries in elite female soccer players. Am J Sports Med. 2014;42(4):940-948. PMID: 24500914.

36. Padua DA, DiStefano LJ, Beutler AI, de la Motte SJ, DiStefano MJ, Marshall SW. The Landing Error Scoring System as a screening tool for an anterior cruciate ligament injury-prevention program in elite-youth soccer athletes. J Athl Train. 2015;50(6):589-595. PMID: 25811846.

37. Paterno MV, Schmitt LC, Ford KR, et al. Biomechanical measures during landing and postural stability predict second anterior cruciate ligament injury after anterior cruciate ligament reconstruction and return to sport. Am J Sports Med. 2010;38(10):1968-1978. PMID:20702858.

38. Plisky PJ, Rauh MJ, Kaminski TW, Underwood FB. Star Excursion Balance Test as a predictor of lower extremity injury in high school basketball players. J Orthop Sports Phys Ther. 2006;36(12):911-919. PMID:17193868.

39. Sousa PL, Krych AJ, Cates RA, Levy BA, Stuart MJ, Dahm DL. Return to sport: Does excellent 6-month strength and function following ACL reconstruction predict midterm outcomes? Knee Surg Sports Traumatol Arthrosc. 2017;25(5):1356-1363. PMID: 26205480.

40. Ter Stege MH, Dallinga JM, Benjaminse A, Lemmink KA. Effect of interventions on potential, modifiable risk factors for knee injury in team ball sports: a systematic review. Sports Med. 2014;44(10):1403-1426. PMID: 25001208.

41. Thomée R, Kaplan Y, Kvist J, et al. Muscle strength and hop performance criteria prior to return to sports after ACL reconstruction. Knee Surg Sports Traumatol Arthrosc. 2011;19(11):1798-1805. PMID:21932078.

42. Waldén M, Krosshaug T, Bjorneboe J, Andersen TE, Faul O, Hägglund M. Three distinct mechanisms predominate in non-contact anterior cruciate ligament injuries in male professional football players: a systematic video analysis of 39 cases. Br J Sports Med. 2015;49(22):1452-1460. PMID:25907183.

43. Webster KE, Feller JA. Clinical Tests Can Be Used to Screen for Second Anterior Cruciate Ligament Injury in Younger Patients Who Return to Sport. Orthop J Sports Med. 2019;7(8):2325967119863003. PMID: 31431901.

44. Webster KE, Hewett TE. What is the Evidence for and Validity of Return-to-Sport Testing after Anterior Cruciate Ligament Reconstruction Surgery? A Systematic Review and Meta-Analysis. Sports Med. 2019;49(6):917-929. PMID: 30905035 
45. Welling W, Benjaminse A, Lemmink K, Gokeler A. Passing return to sports tests after ACL reconstruction is associated with greater likelihood for return to sport but fail to identify second injury risk. Knee. 2020. PMID: 32247810.

46. Wellsandt E, Failla MJ, Snyder-Mackler L. Limb Symmetry Indexes Can Overestimate Knee Function After Anterior Cruciate Ligament Injury. J Orthop Sports Phys Ther. 2017;47(5):334-338. PMID: 28355978 


\section{Supplementary Appendix.}

The validity of the 5 tests with 10 different test cut-offs to predict a new traumatic severe knee injury are presented in Figure 1 (postural control), Figure 2 (hop performance, endurance and maximum) and Figure 3 (hop performance, movement asymmetries).
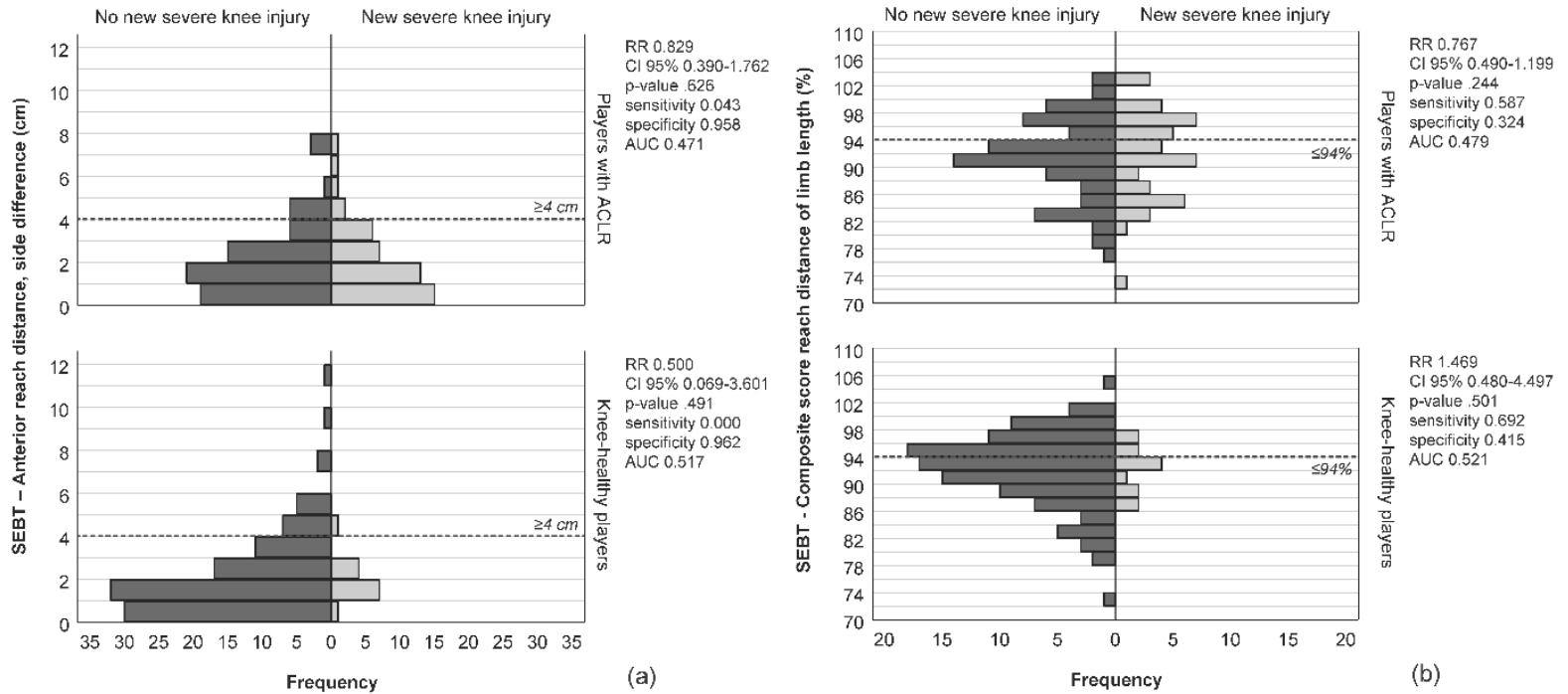

Figure 1. Postural control: risk ratio (RR), $95 \%$ confidence interval (CI), $P$ value for the 2 cohorts, players with ACLR and knee-healthy players, comparing the proportion of players with cutoffs defining a high or low-risk player, and sustaining a new traumatic severe knee injury: (a) $\geq 4 \mathrm{~cm}$ side difference in anterior reach distance and (b) $\leq 94 \%$ of limb length in composite score in the Star Excursion Balance Test (SEBT). The predictive validity of the cutoffs was assessed with receiver operating characteristic curve statistics with area under the curve (AUC), sensitivity, and specificity.
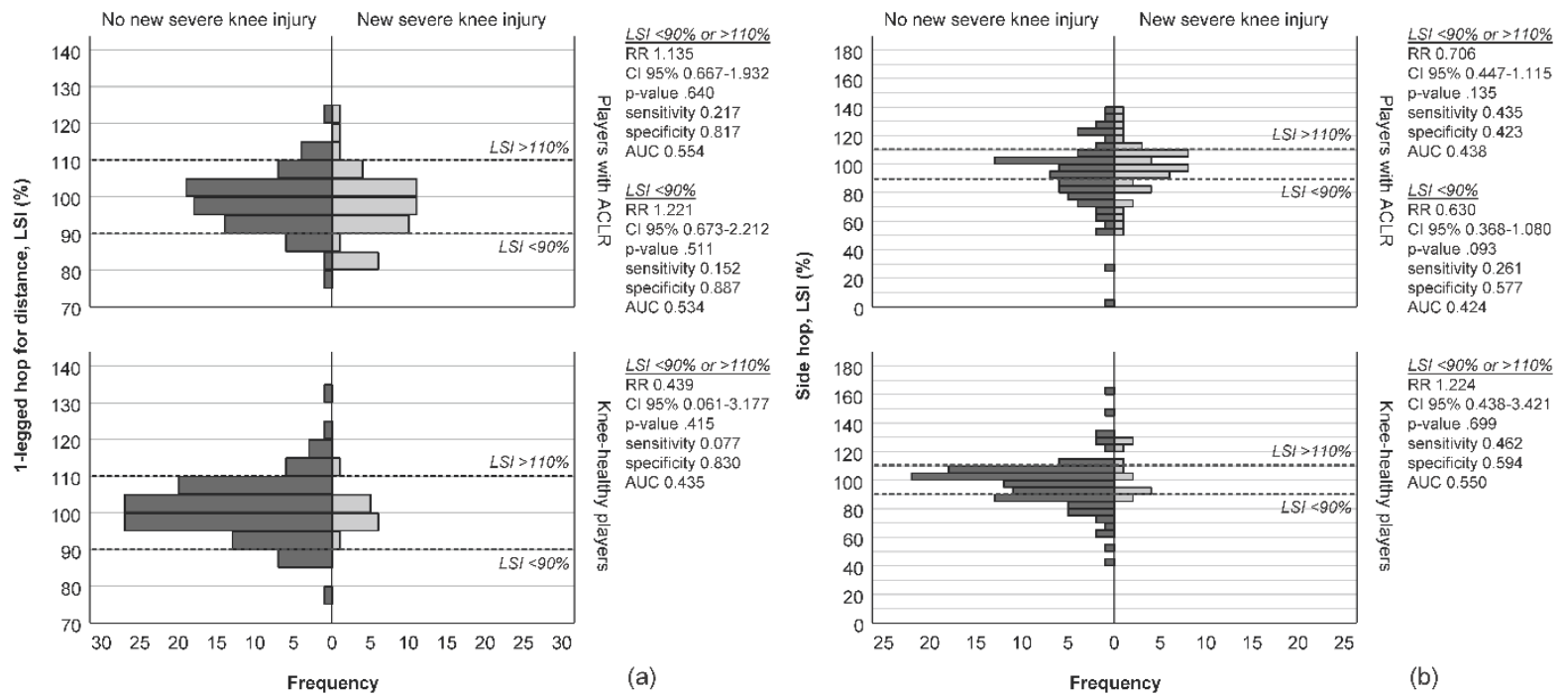

Figure 2. Hop performance: risk ratio (RR), 95\% confidence interval (CI), $P$ value for the 2 cohorts, players with ACLR and knee-healthy players, comparing the proportion of players with cutoffs defining a high or lowrisk player, and sustaining a new traumatic severe knee injury: (1) Limb Symmetry Index (LSI) $<90 \%,(2)<90 \%$ or $>110 \%$, i.e., the ACLR limb should neither not be $10 \%$ weaker or stronger compared with the nonreconstructed leg in (a) 1-legged hop for distance and (b) side hop. The predictive validity of the cutoffs was assessed with receiver operating characteristic curve statistics with area under the curve (AUC), sensitivity, and specificity. 

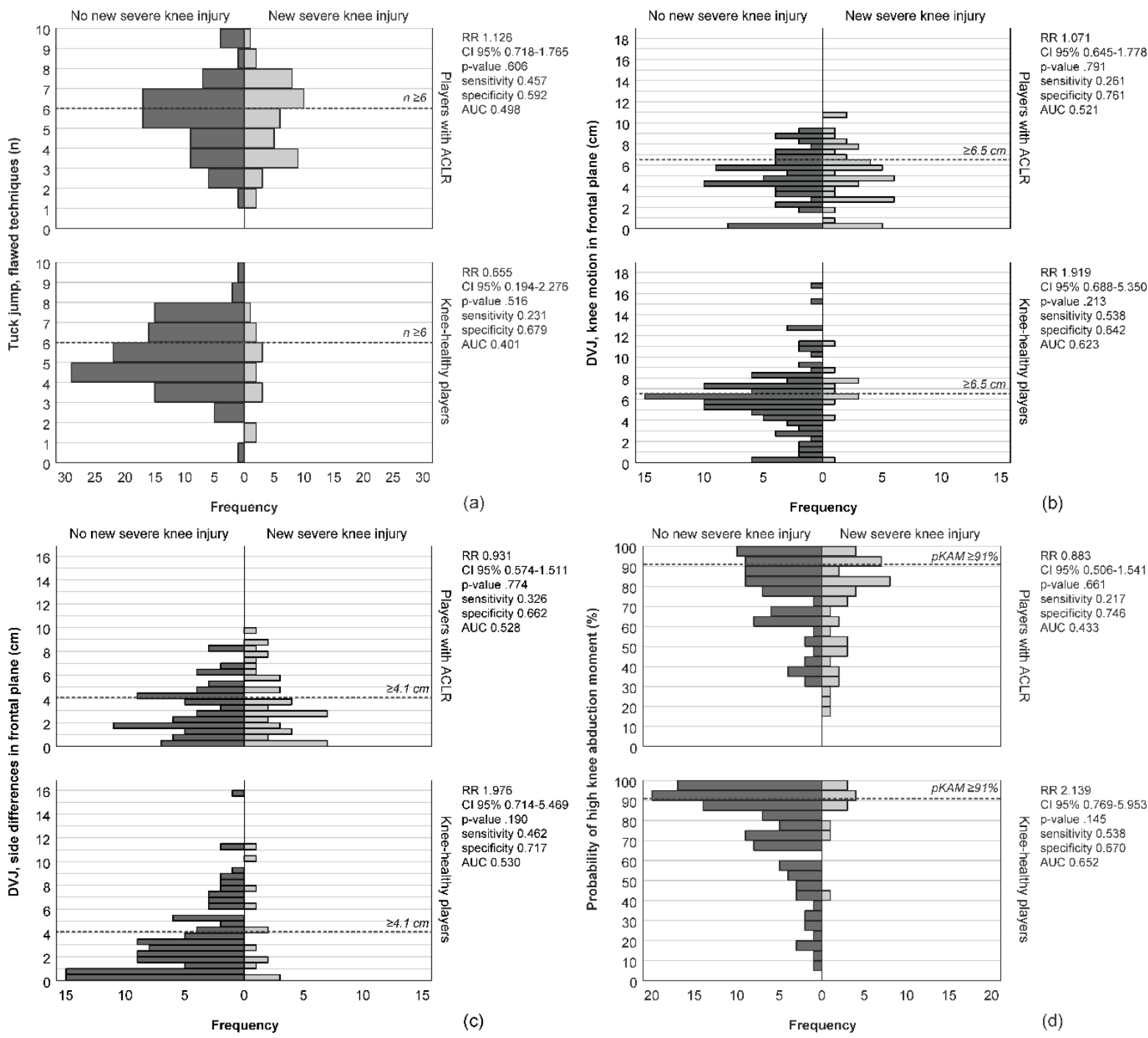

(a)

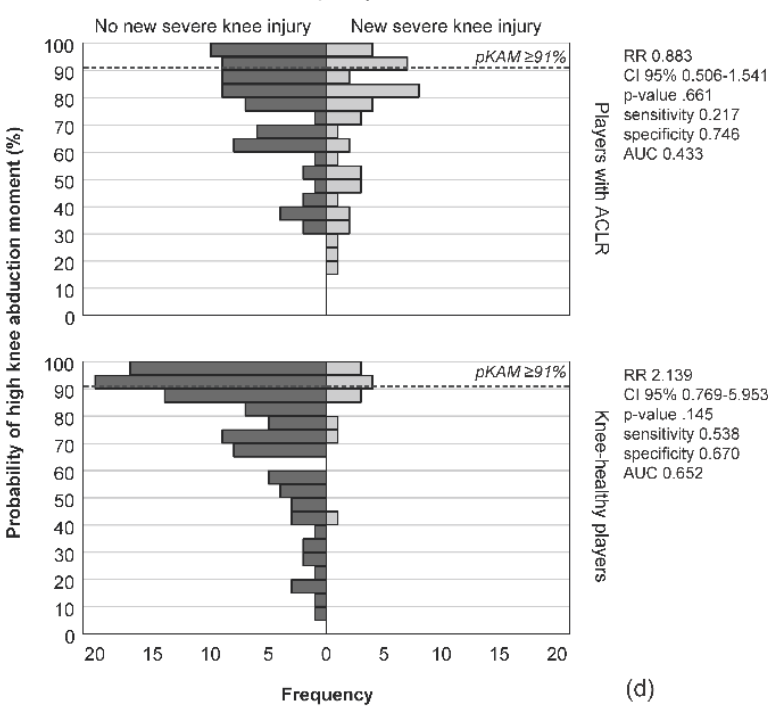

Figure 3. Movement asymmetries in the lower limbs and trunk: risk ratio (RR), $95 \%$ confidence interval (CI), $P$ value for the 2 cohorts, players with ACLR and knee-healthy players, comparing the proportion of players with cutoffs defining a high or low-risk player, and sustaining a new traumatic severe knee injury; (a) $\geq 6$ flawed techniques in the tuck jump, (b) knee valgus motion $\geq 6.5 \mathrm{~cm}$ in any knee, (c) $\geq 4.1 \mathrm{~cm}$ side difference in frontal plane, (d) probability of high knee abduction moment (pKAM) $\geq 91 \%$ in drop vertical jump (DVJ) and sustaining a new ACL injury. The predictive validity of the cutoffs was assessed with receiver operating characteristic curve statistics with area under the curve (AUC), sensitivity, and specificity.

The validity of the 5 tests with 10 different test cut-offs to predict a rerupture of the ACL graft are presented in figure 4 (postural control), figure 5 (hop performance, endurance and maximum) and figure 6 (hop performance, movement asymmetries). 

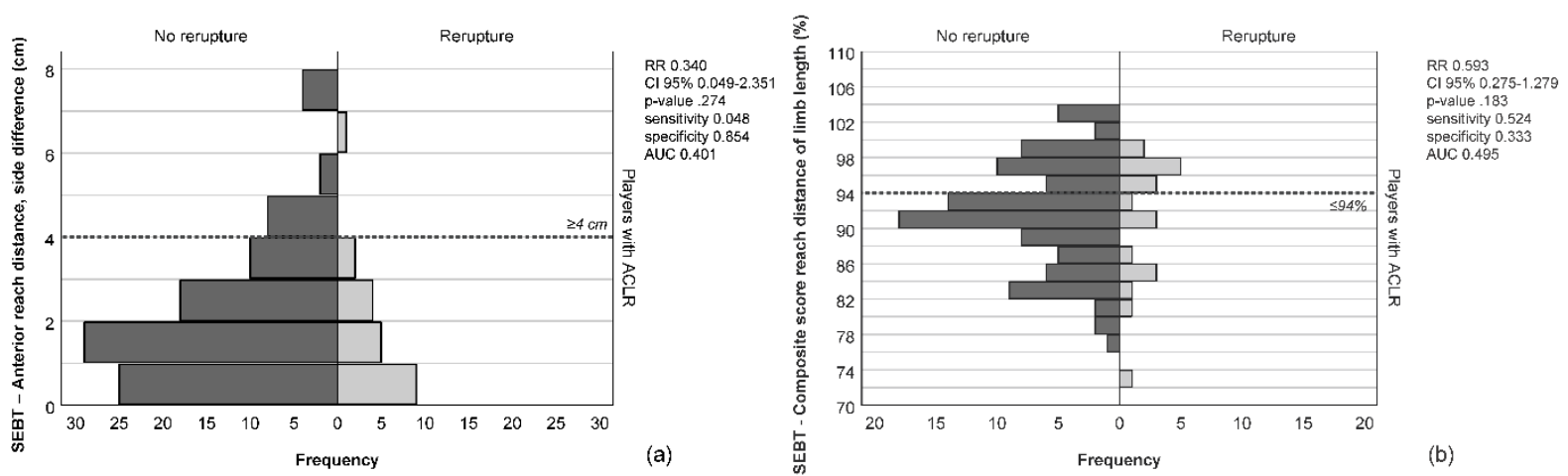

Figure 4. Postural control: risk ratio (RR), 95\% confidence interval (CI), $P$ value for players with ACLR, comparing the proportion of players with cutoffs defining a high or low-risk player, and sustaining a rerupture of the ACL graft: (a) $\geq 4 \mathrm{~cm}$ side difference in anterior reach distance and (b) $\leq 94 \%$ of limb length in composite score in the Star Excursion Balance Test (SEBT). The predictive validity of the cutoffs was assessed with receiver operating characteristic curve statistics with area under the curve (AUC), sensitivity, and specificity.
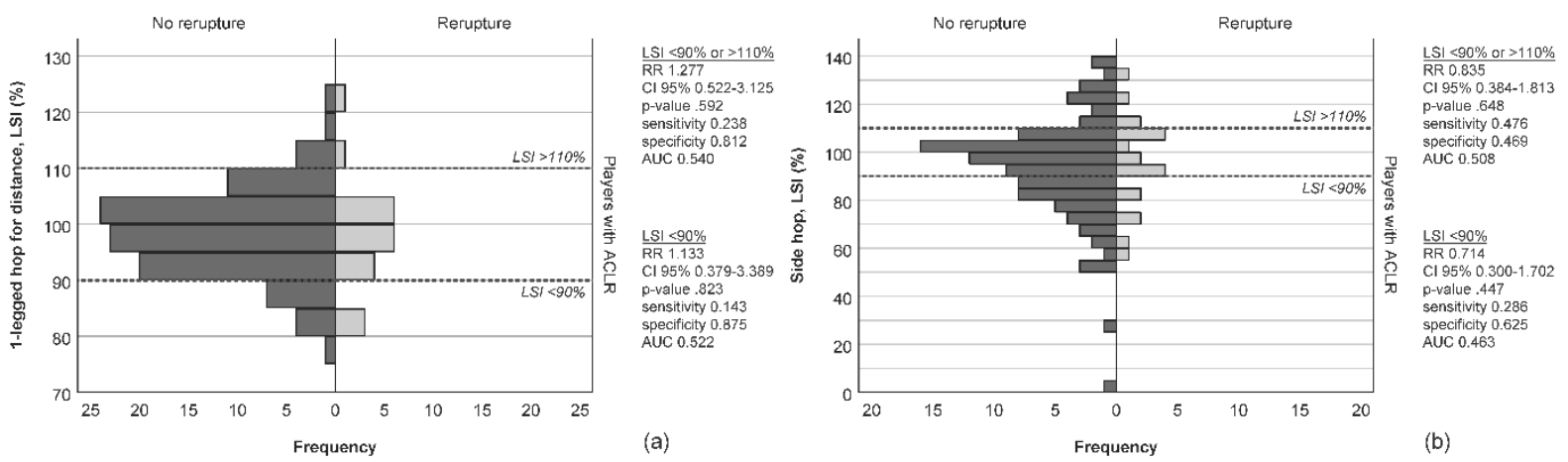

Figure 5. Hop performance: risk ratio (RR), 95\% confidence interval (CI), $P$ value for the players with ACLR, comparing the proportion of players with cutoffs defining a high or low-risk player, and sustaining a rerupture of the ACL graft: (1) Limb Symmetry Index (LSI) $<90 \%$, (2) $<90 \%$ or $>110 \%$, i.e., the ACLR limb should neither not be $10 \%$ weaker or stronger compared with the non-reconstructed leg in (a) 1-legged hop for distance and (b) side hop. The predictive validity of the cutoffs was assessed with receiver operating characteristic curve statistics with area under the curve (AUC), sensitivity, and specificity. 

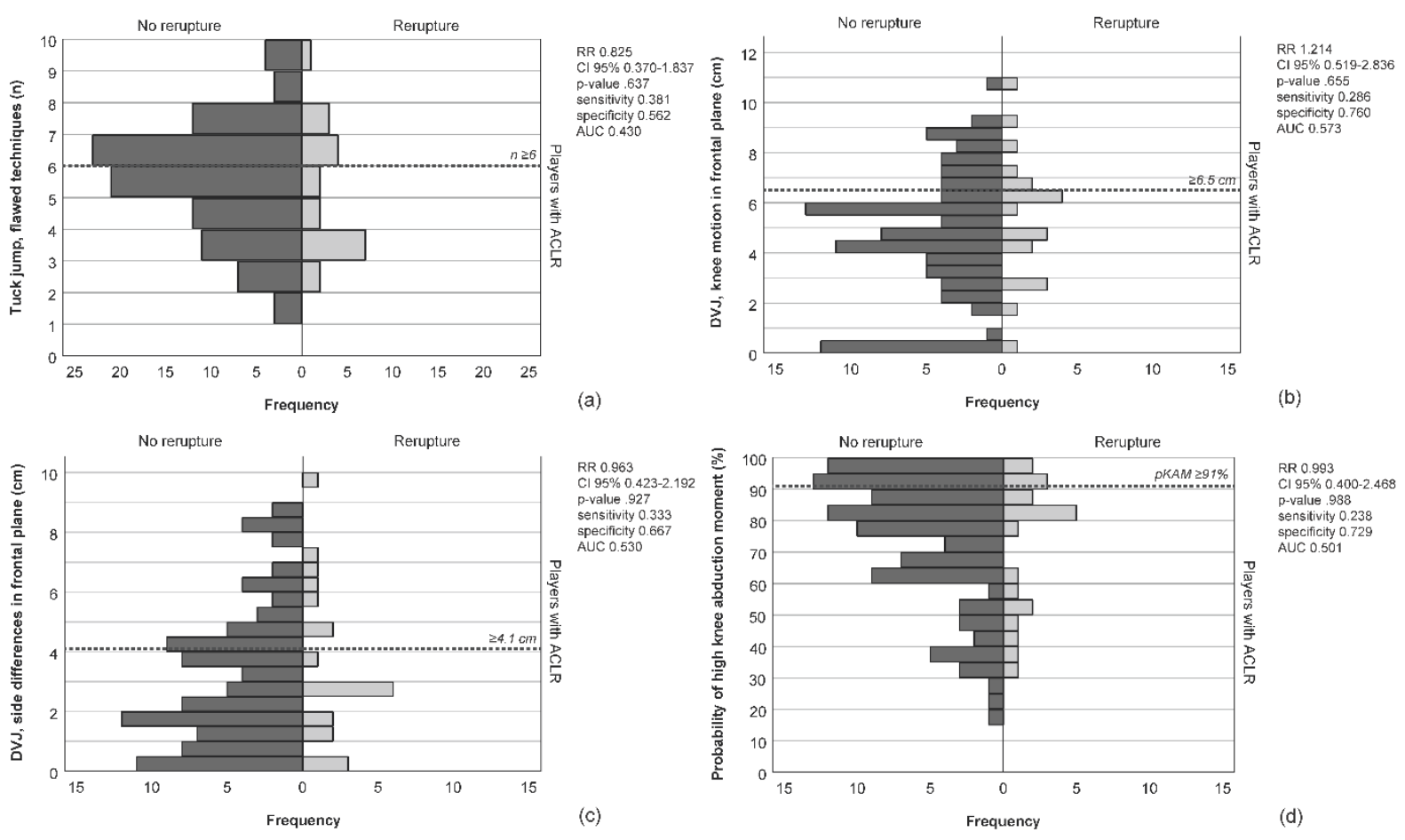

Figure 6. Movement asymmetries in the lower limbs and trunk: risk ratio (RR), $95 \%$ confidence interval (CI), $P$ value for the players with ACLR, comparing the proportion of players with cutoffs defining a high or low-risk player, and sustaining a rerupture of the ACL graft; (a) $\geq 6$ flawed techniques in the tuck jump, (b) knee valgus motion $\geq 6.5 \mathrm{~cm}$ in any knee, (c) $\geq 4.1 \mathrm{~cm}$ side difference in frontal plane, (d) probability of high knee abduction moment (pKAM) $\geq 91 \%$ in drop vertical jump (DVJ) and sustaining a new ACL injury. The predictive validity of the cutoffs was assessed with receiver operating characteristic curve statistics with area under the curve (AUC), sensitivity, and specificity.

The validity of the 5 tests with 10 different test cut-offs to predict a contralateral ACL injury are presented in figure 7 (postural control), figure 8 (hop performance, endurance and maximum) and figure 9 (hop performance, movement asymmetries).
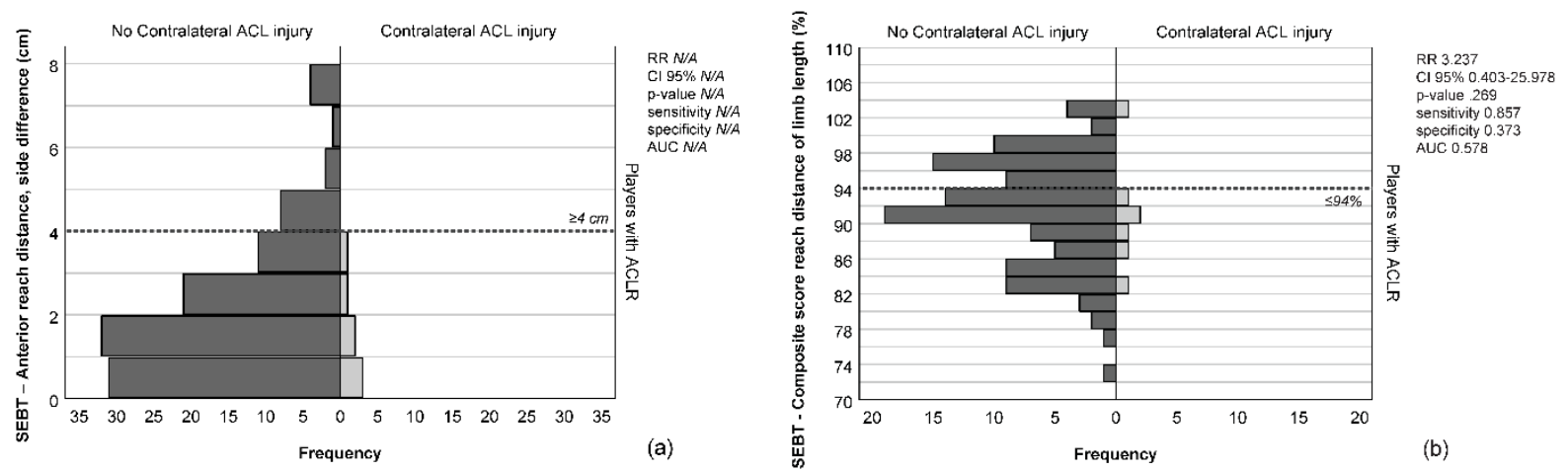

Figure 7. Postural control: risk ratio (RR), 95\% confidence interval (CI), $P$ value for the players with ACLR, comparing the proportion of players with cutoffs defining a high or low-risk player, and sustaining a contralateral ACL injury: (a) $\geq 4 \mathrm{~cm}$ side difference in anterior reach distance and (b) $\leq 94 \%$ of limb length in composite score in the Star Excursion Balance Test (SEBT). The predictive validity of the cutoffs was assessed with receiver operating characteristic curve statistics with area under the curve (AUC), sensitivity, and specificity. 

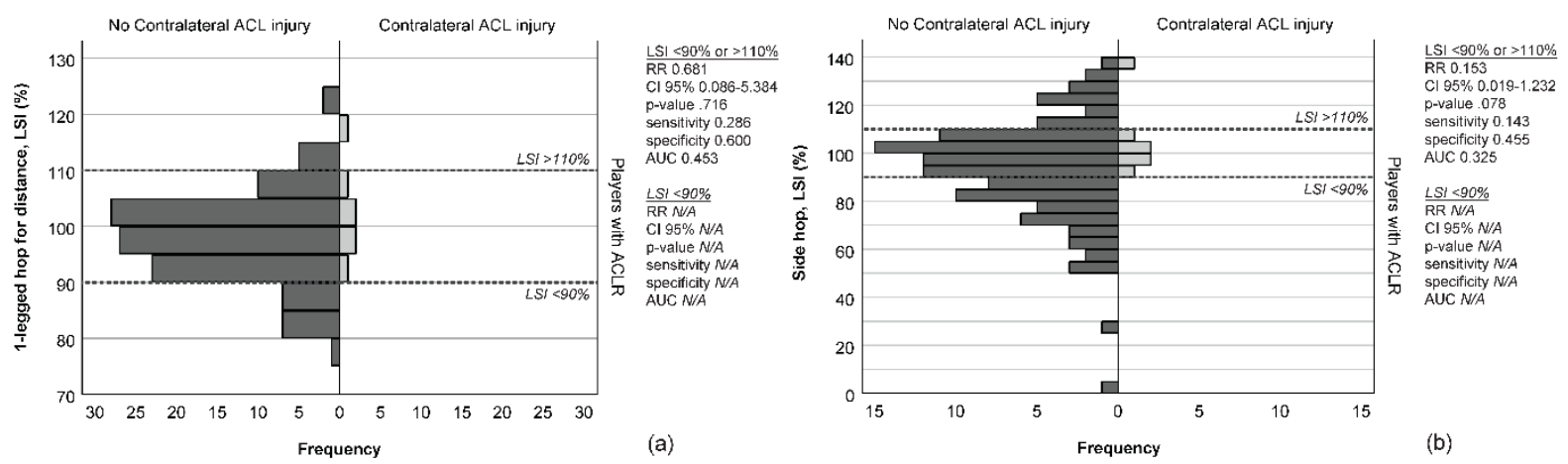

Figure 8. Hop performance: risk ratio (RR), 95\% confidence interval (CI), $P$ value for the players with ACLR, comparing the proportion of players with cutoffs defining a high or low-risk player, and sustaining a contralateral ACL injury: (1) Limb Symmetry Index (LSI) $<90 \%$, (2) $<90 \%$ or $>110 \%$, i.e., the ACLR limb should neither not be $10 \%$ weaker or stronger compared with the non-reconstructed leg in (a) 1-legged hop for distance and (b) side hop. The predictive validity of the cutoffs was assessed with receiver operating characteristic curve statistics with area under the curve (AUC), sensitivity, and specificity.
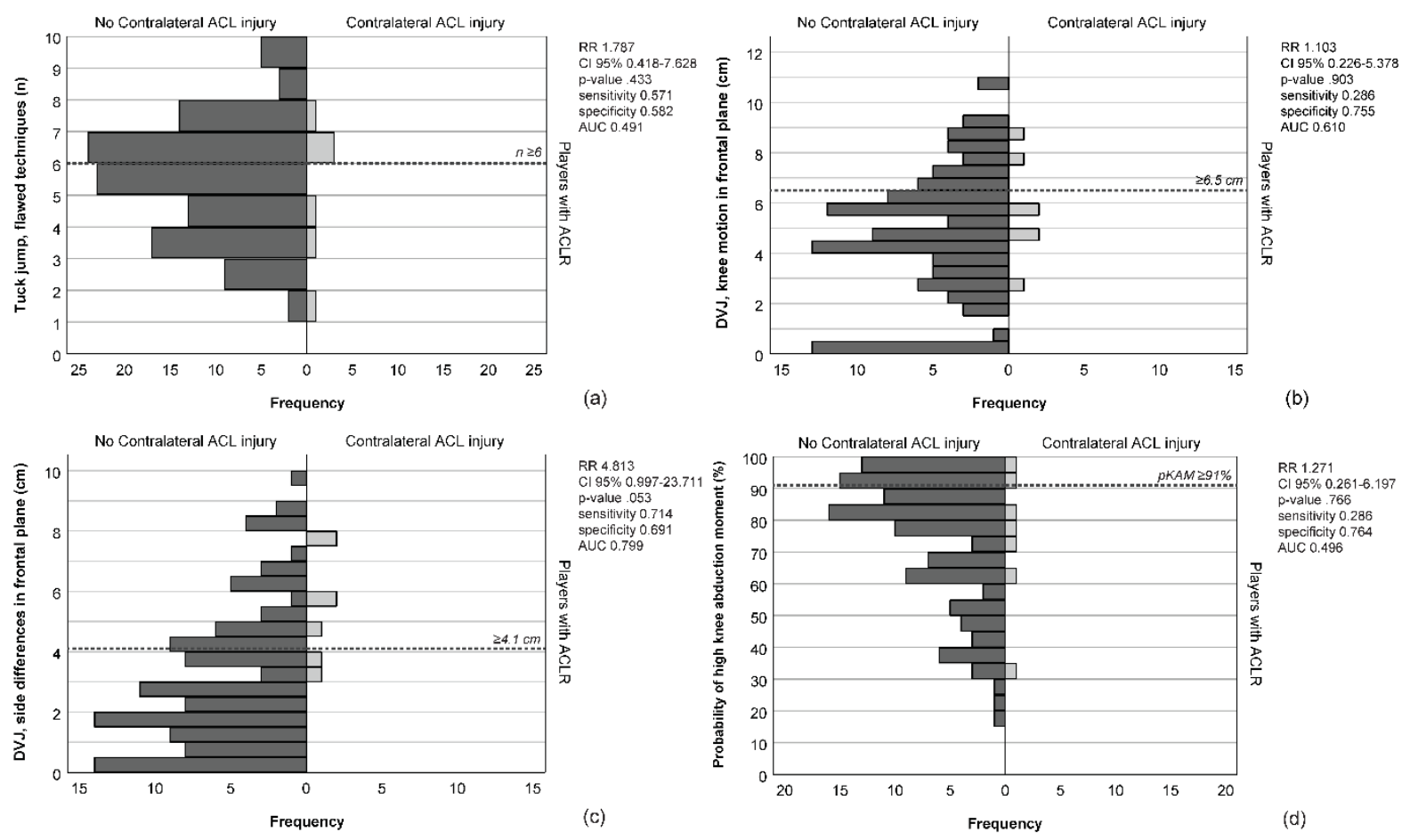

Figure 9. Movement asymmetries in the lower limbs and trunk: risk ratio (RR), $95 \%$ confidence interval (CI), $P$ value for the players with ACLR, comparing the proportion of players with cutoffs defining a high or low-risk player, and sustaining a contralateral ACL injury; (a) $\geq 6$ flawed techniques in the tuck jump, (b) knee valgus motion $\geq 6.5 \mathrm{~cm}$ in any knee, (c) $\geq 4.1 \mathrm{~cm}$ side difference in frontal plane, (d) probability of high knee abduction moment (pKAM) $\geq 91 \%$ in drop vertical jump (DVJ) and sustaining a new ACL injury. The predictive validity of the cutoffs was assessed with receiver operating characteristic curve statistics with area under the curve (AUC), sensitivity, and specificity. 